\title{
UMA QUESTÃO AMBIENTAL
}

"Há mais coisas entre o céu e a terra, do que sonha a nossa vã filosofia"

William Shakespeare

\author{
Jailton José da Silva ${ }^{1}$
}

RESUMO: A Conferência das Nações Unidas sobre desenvolvimento e Meio Ambiente Humano, tentou sensibilizar sobre a responsabilidade de cada nação no tocante à degradação do meio ambiente, além dos danos que causam a segregação, discriminação e a opressão colonial, dentre outros. A evolução trouxe o Direito Ambiental, o qual versa sobre matéria difusa, por isso, é importante e substancial para um bom entrosamento entre meio ambiente e desenvolvimento sustentável, pois é ele que dá sentido ao tripé da sustentabilidade, representados pelos segmentos econômico, social e ambiental. A proteção do Meio Ambiente visada pelo direito ambiental encontra barreiras em todos os campos, mas principalmente quando debate com os setores econômicos, os quais, são responsáveis pela confusão e distorção de valores, que se ampliam e se disseminam pelas mentes e ações de todos, todavia, mais notadamente entre a população carente, que, embora servindo de massa de manobra, a esses é atribuída a culpa pelo insucesso. Entre os anos 2020 e 2021, a justiça brasileira viveu às voltas com denúncias contra o Ministro do Meio Ambiente, homem de confiança do governo Bolsonaro, o qual foi acusado de facilitar o desmatamento no país. Entre os anos 2020 e 202I, a justiça brasileira viveu às voltas com denúncias contra o Ministro do Meio Ambiente, homem de confiança do governo Bolsonaro, o qual foi acusado de facilitar o desmatamento no país.

Palavras- chave: Direito ambiental. Desmatamento. Meio ambiente.

\section{INTRODUÇÃO}

A Conferência de Estocolmo/72, (Conferência das Nações Unidas sobre desenvolvimento e Meio Ambiente Humano), teve seu principal foco a paz entre as nações e iniciou a discussão sobre como preservar e melhorar o ambiente humano. Cria-se o termo "Eco-desenvolvimentista", algo próximo ao desenvolvimento sustentável.

\footnotetext{
${ }^{1}$ Servidor público - SMS - São PauloLicenciatura em Sociologia - UNIP- Universidade Paulista. Curso Superior de Tecnologias em Gestão Ambiental pela Universidade Cidade de São Paulo- UNICID. Pósgraduação Latu sensu em psicanálise-Faculdade Famart.E-mail jzoonoses@bol.com.br
} 
Apresentou como fatores essenciais à vida: Eficiência econômica, igualdade social e equilíbrio ecológico. Entretanto, foi na RIO/92 que as normas e metas de proteção ambiental começaram a ganhar corpo e influenciar de forma decisiva no cenário nacional e internacional.

Aquele documento, tentou sensibilizar sobre a responsabilidade de cada nação no tocante à degradação do meio ambiente, além dos danos que causam a segregação, discriminação e a opressão colonial, dentre outros. "A Conferência de Estocolmo foi importante por ter sido a primeira reunião deste porte a tratar de assuntos ligados à proteção do meio ambiente e por promover a criação do Programa das Nações Unidas para o Meio Ambiente (PNUMA), tornando-se a primeira agência ambiental de âmbito

\section{Queimada na Amazônia- Arquivo - wwwi2.senado.leg.br}

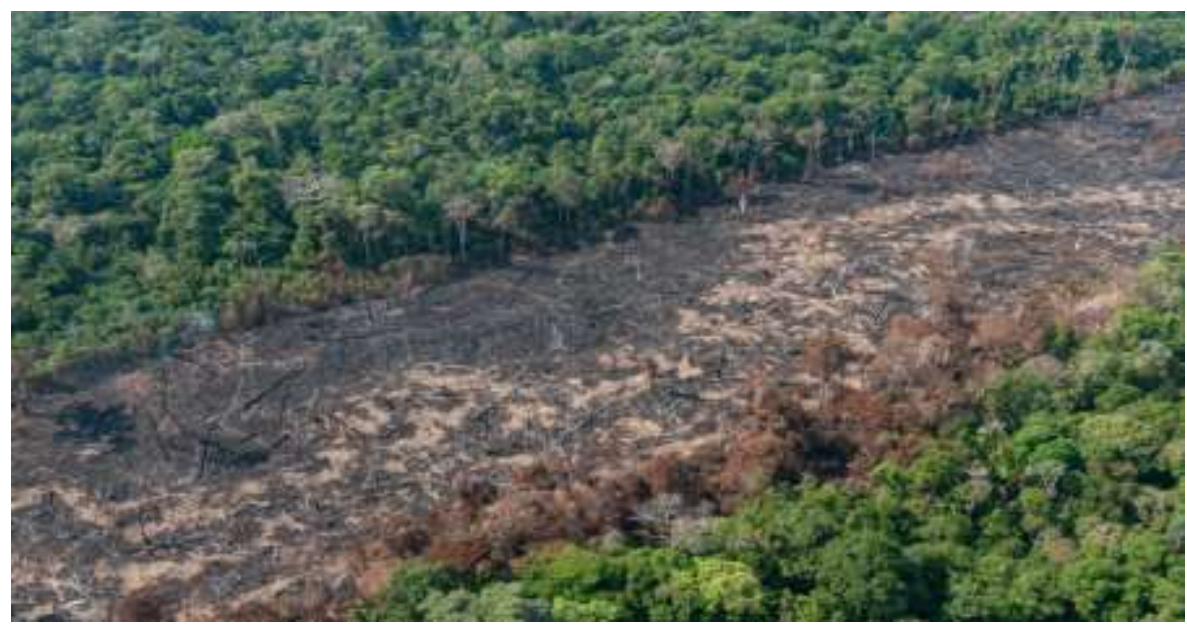

A evolução trouxe o Direito Ambiental, o qual versa sobre matéria difusa, por isso, é importante e substancial para um bom entrosamento entre meio ambiente e desenvolvimento sustentável, pois é ele que dá sentido ao tripé da sustentabilidade, representados pelos segmentos econômico, social e ambiental.

Embora achemos que nada é feito, em relação ao meio ambiente, podemos pensar que essa luta ainda não é de todos, e que, apenas o discurso consegue ter uma certa ressonância, mas sua efetividade pode ser facilmente contestada.

Vivemos em uma época onde confundimos muitas coisas, às vezes induzidos, e outras por falta de visão abrangente, porquanto, não temos como imaginar, como seria se a 
luta de alguns não tivesse chegado a tal conquista, a ponto de conversarmos hoje em direito ambiental.

Temos que valorizar as conquistas e sempre nos perguntar porque não deu certo. Nenhuma lei será efetiva se não interiorizada, então podemos dizer que esse segmento do direito ainda não se livrou da imagem de uma imposição, sendo assim, é uma moral hegemônica, mas não é homogênea, sujeita a interpretações, terá dificuldades para promover resultados visíveis, ainda mais quando em um país como o Brasil, onde o sentido da palavra cidadania vive atrelado à politicagem e vista apenas como o exercício da participação e busca de direitos. Entendemos como moral, toda discussão que resulta em consenso.

A proteção do Meio Ambiente visada pelo direito ambiental encontra barreiras em todos os campos, mas principalmente quando debate com os setores econômicos, os quais, são responsáveis pela confusão e distorção de valores, que se ampliam e se disseminam pelas mentes e ações de todos, todavia, mais notadamente entre a população carente, que, embora servindo de massa de manobra, a esses é atribuída a culpa pelo insucesso. Além do mais, a discussão sobre esse tema só se acirra quando há grandes desastres ou em respostas à solicitação da ONU (Organização das Nações Unidas). Entretanto, não abandona sua face alienante e narcísica, distanciando-se de ações empoderadoras.

Entre os anos 2020 e 2021, a justiça brasileira viveu às voltas com denúncias contra o Ministro do Meio Ambiente, homem de confiança do governo Bolsonaro, o qual foi acusado de facilitar o desmatamento no país. Como assim, esse ministério não foi criado para evitar o colapso ambiental? Isso deve ser coisa da esquerda, não?

Deutsche Welle é uma emissora internacional da Alemanha e publicou a seguinte matéria pela Repórter Nádia Pontes:

Para o MPF (Ministério Público Federal), Salles decidiu encolher as estruturas do Estado responsáveis pelo combate ao desmatamento e às queimadas e reduzir o papel do IBAMA, de maneira ilegal". A ação estima que, em 2019, sob a gestão de Salles, 318 mil quilômetros quadrados de florestas viraram cinzas - um recorde. Também houve aumento nas taxas mensais de desmatamento”. Nádia Pontes (o8/o7/2020) https://www.dw.com/pt-br/as-acusa

Enquanto isso, os reles mortais do baixo povo, são orientados a respeitar a natureza, preservá-la e, se não cumprir a legislação e cortar uma árvore, poderá ser preso e 
pagar multa por dano ambiental. Tá certo isso? Sim, faz parte da educação popular, porém o sistema não sai de casa em casa procurando quem cortou um galho de arvore em seu quintal, entretanto, estamos atravessando uma era onde as pessoas escondem seus próprios feitos e apontam o alheio, ou seja, vulgarmente falando, a era do dedo duro.

As pessoas denunciam seus iguais, seu vizinho, desde que ele não seja seu amigo, então denunciam por birra, não pelo carinho que a natureza merece, não denunciam ocupações irregulares, queimadas em grande escala, pessoas que ganham para descartar irregularmente entulhos, dizem ser de responsabilidade do poder publico, então reina o exagero, pois toda denuncia registrada deve ser averiguada.

As leis criadas fazem parte do consenso de que precisamos preservar o meio ambiente dos abusos humanos, o espírito delas é educativo, por isso são publicadas para que todos tenham acesso, mas parece que o ministro que deveria ser a maior autoridade e incentivador do cumprimento delas esqueceu disso.

O Dr. SAMAHA, associado ao Escritório Pinheiro Pedro Advogados, chama a atenção e esclarece que:

Caso uma árvore seja cortada sem autorização da prefeitura, o proprietário deverá pagar $\mathrm{R} \$$ Io.00o,oo ( $\mathrm{dez}$ mil reais) por árvore, além de ser obrigado a compensar o corte ilegal com o plantio de considerável número de mudas. Ademais, a SVMA, após multar o proprietário na esfera administrativa, comunicará a delegacia de polícia para tomar as providências cabíveis no âmbito criminal, podendo o “criminoso" ser preso por até 03 (três) anos e pagar outra multa...

Além da multa pelo dano ambiental, o proprietário poderá ser notificado a pagar multa pela falta de autorização para o corte de árvores, conforme previsto na Lei no $10.365 / 87$, segundo entendimento do órgão ambiental municipal...” Edgard Dagher Samaha(wwwdazibao.com.br)

Estamos sempre contando os cinco R's (Repensar, Recusar, Reduzir, Reutilizar e Reciclar), léxicos salvadores. Sendo tão salvadores, porque só os pobres são obrigados a colocá-los em prática, será que é pelo fato dessa categoria de pessoas dominarem mais as tecnologias?

Repensar a minha necessidade, recusar o que não necessito, recusar aquilo que não conhece o histórico, ou que tenha histórico danoso. Reduzir o consumo desnecessário e reutilizar para reduzir os degradantes do ambiente. Nesse Reutilizar, o que mais preocupa é a questão da borracha, em particular "os pneus". Encontramos pneumáticos sendo reutilizados por todo lado, em praças, jardins, em playground, e até mesmo em artesanatos. Já há literaturas que indicam o alto teor de toxidade trazido na composição desses resíduos, sem falar que, no setor urbano, já existem as chamadas ilhas de calor e que a borracha contribuirá com seu agravamento, pois aquece 


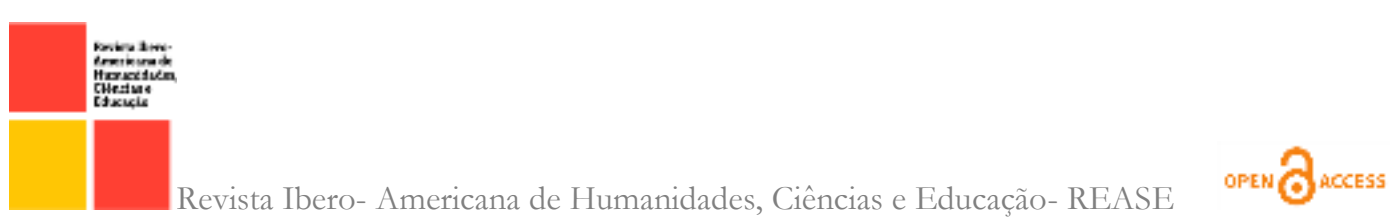

fácil e mantém a temperatura por mais tempo. Já há trabalhos acadêmicos que indicam possibilidade de prejuízos para a saúde provocados pela reciclagem da borracha, como a grama sintética. Eles também indicam os riscos trazidos por tóxicos eliminados por pneus descartados irregularmente.

Fora isso, podemos pensar como serão as cidades, se continuarmos usando os pneus para fazer assentos, muros de arrimos, balanços para crianças e outros inventos... Será que estamos caminhando para a criação de cidades de borracha, mas... e a relação das características da borracha com o aquecimento global?

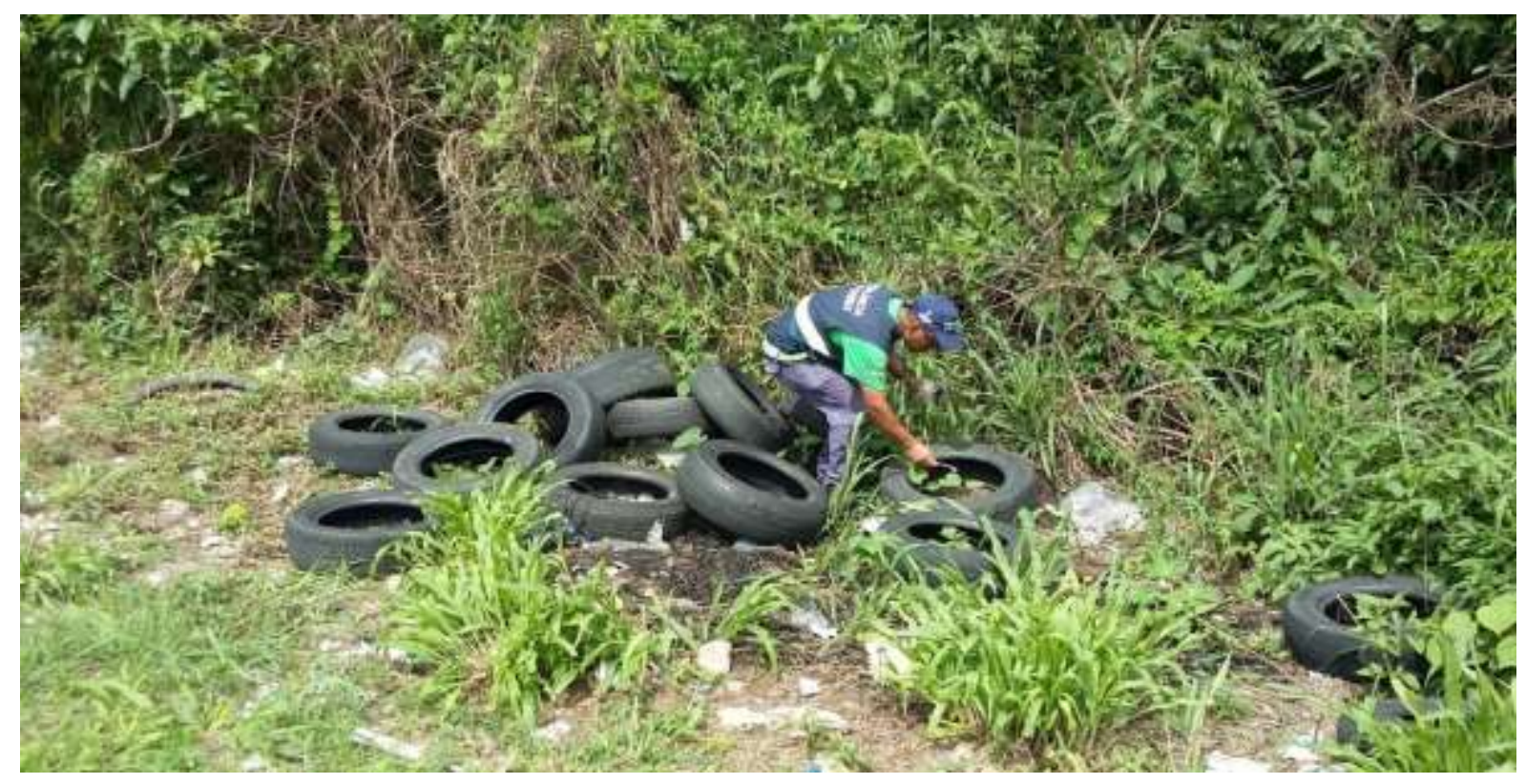

Foto pneus - arquivo próprio

Conforme SOUZA,2009 apud PARRA et al, no artigo Reutilização e Reciclagem de

Pneus, e os Problemas Causados por sua destinação incorreta:

[...]A queima de pneus sem nenhum tipo de tratamento ou filtro de fumaça... podem representar riscos de mortalidade prematura, problemas do coração, depressão do sistema nervoso e central (SOUZA,2009). [...] A queima a céu aberto de pneumáticos contamina o ar com sua fumaça composta de carbono $e$ dióxido de enxofre, além de poluir o solo com grande quantidade de óleo que poderá infiltrar e contaminar o lençol freático. (Cristina Vilela Parra et al)

Além dos danos que podem causar a saúde humana e ao meio ambiente, como um todo, esses resíduos são atrativos para mosquitos transmissores de arboviroses como dengue, febre amarela e outros, transformando-os, por sua forma concava, em potenciais criadouros. 
Já existem registros de utilização de pneumáticos na produção de energia, asfalto e outros, mas ainda são consideradas tecnologias de alto investimento, isto desencoraja os administradores e empresários. No entanto, encontramos incentivos para a utilização desses resíduos em locais abertos e em artigos artísticos. Agindo assim, não estaríamos liberando o empresariado de suas obrigações enquanto oneramos o meio ambiente?

As siglas IPVA, DPVAT e o CRLV, são impostos cobrados aos proprietários de veículos, mas, onde são aplicados esses valores e por que a lei que doutrina a história dos pneus, aparentemente tem dificuldades para sair do papel à prática? Ou será que esse povo que tem carro, paga pouco pelo seu bem e por isso devem arcar com esse ônus?

Essa história de meio ambiente é só mais uma enganação da esquerda, né, ou será da direita?

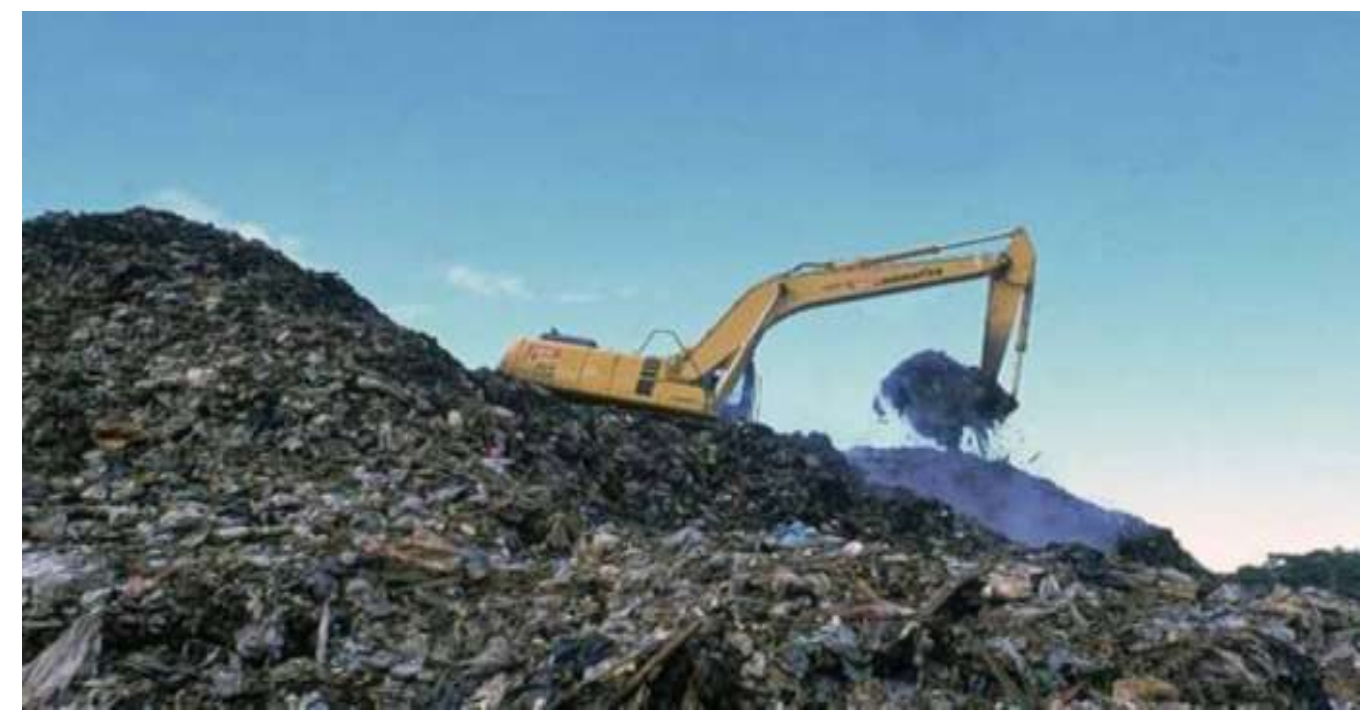

Foto - Lixão no Rio de Janeiro- Arquivo - exame.com

\section{MUNDO SUSTENTÁVEL}

O termo sustentabilidade ambiental surgiu na Conferência das Nações Unidas em 1972, em Estocolmo, e está ligado ao processo de uma geração viver dignamente em seu ambiente e época, sem alterar os direitos das próximas gerações.

Quando há um movimento no interior da terra, notamos de forma significativa suas consequências na superfície, modelando, transformando e destruindo. Fazendo com 
que o homem se lembre que não é ele o centro do planeta, e que essa história de antropocentrismo pode não ser bem aceita pelo anfitrião da raça humana, o planeta Terra.

Os movimentos sísmicos trazem novas paisagens e grandes transformações na vida material e espiritual dos habitantes humanos, também dos inumanos, todos que compõem a fauna e flora, todavia, podemos pensar que de acordo com a magnitude do evento, estes últimos sofrem mais, entretanto, como medir o sofrimento de uma família de castores, de rãs, de búfalos, que precisam abandonar seu habitat de forma inesperada e às vezes fora de época, após ou antecipando um terremoto, por exemplo. Para onde irão, ou onde estarão os habitantes da planície, ou daquela montanha que desapareceu?

Como é o solicitado pelo ensaio dessa discussão, e em nome da teoria que põe o humano no centro de tudo, vamos introduzir nesse ensejo seu sofrimento, já que é o mais famoso terráqueo, mesmo não sendo o mais importante. Também, não seria estranho que um homem exaltasse outra raça senão a sua própria?

Um abalo que atinge a superfície, obrigando-a a se movimentar, ele a remodela, causando simultaneamente emigração e imigração. Pode levar a umidade onde era seco e criar montanhas ou vales, onde essas características não eram percebidas.

Nenhum movimento significativo acontecerá sem deixar marcas na crosta superficial e alterações nas vidas e mentes humanas. Temos exemplos de países que tiveram a vida de seus habitantes ceifadas em grande parte, enquanto outros tiveram que refazê-las em outros lugares.

Quando a natureza é caprichosa, ela obriga o homem a engolir sua arrogância e a reaprender a viver, a partir do caos. Perdem-se casas, vidas e orgulho, juntam-se os opostos! Entretanto, os famosos de bípedes e polegares opositores, ainda se lançam em aventuras exploratórias nas profundezas da terra, para a produção de energia.

Nessa linha de raciocínio, citamos o Fracking, tecnologia usada para retirada de gás de xisto. Essa coleta é feita a mais de 3.200 metros no solo. Consiste em explodir as rochas pela injeção de água e produtos químicos. Não alteram com isso apenas a parte física das rochas, os gases e os produtos químicos, segundo estudiosos, podem ser cancerígenos e parte deles voltam para a superfície.

\footnotetext{
Alguns estudos mostram que mais de $90 \%$ de fluidos resultantes do fracking podem permanecer no subsolo. O flowback, fluído do fraturamento que retorna à superfície, normalmente armazenado em lagoas abertas ou tanques no local do
} 
poço, também causa impactos como a contaminação do solo, ar e lençóis de água subterrânea." Portal Não Fracking Brasil

https://naofrackingbrasil.com.br/o-que-e-fracking/

O que buscamos? Meios de gerar energia ou de gerar capital?

Há muitas invenções e descobertas na área de produção de energia, entretanto, não encontramos uma intenção de uso até à exaustão.

Essas inúmeras formas de produção de energia são deixadas de lado a cada vez que há uma nova descoberta, quando não, são desencorajadas por falta de investimento, então saímos por aí furando o planeta, poluindo as águas e dizemos que é porque a população está crescendo e precisamos de novas fontes.

É notório o desperdício de energia por todos os lugares onde passamos, seja por não aproveitar as potencialidades, ou a falta de responsabilidade com a já produzida.

A demanda de energia não é apenas uma questão de produção, mas também uma questão de gestão, de educação e compromisso, coisa que não se tem em nossos atuais políticos e, aos poucos, e em um estágio já avançado, também está interiorizado no povo, mas esse último será o culpado, o bode expiatório.

Observa-se nos últimos tempos o aparecimento de formas de gerar energia, mas as que realmente importam são aquelas que dão status e permitem que os empresários possam imprimir uma falsa ideia de autossuficiência.

Ainda não se valoriza o suficiente à matéria prima, para falarmos tanto em produção, não se respeita as descobertas e o já produzido, porque o foco é outro, e fica difícil pensar que seja realmente energia para todos.

O gás metano $\left(\mathrm{CH}_{4}\right)$ pode ser um grande aliado nessa busca pela energia, sendo também encontrado em fezes de animais, no lixo doméstico e outros. Esse elemento é um grande influenciador, quando falamos em cuidados com o aquecimento global, chega a ser mais importante que o próprio $\mathrm{CO}_{2}$ (Dióxido de Carbono), devido à sua origem e quantidade, além da sua característica de curta permanência na atmosfera, quando cessada a produção, enquanto que o $\mathrm{CO}_{2}$, mesmo sem novas inserções, durará por séculos.

Conforme texto de Micheli Cain para a revistagalileu.globo.com do mês II/202I, onde, diz a autora: "O metano vaza de poços de petróleo e gás, aterros sanitários e é expelido pelo gado. Os países signatários do acordo abrangem dois terços da economia 
global e metade dos 30 maiores emissores de metano, incluindo o Brasil.” Michelle Cain (revistagalileu.globo.com 03/II/2I)

A Agência Brasil divulgou em 06/2019, matéria sobre a queima irregular de resíduos em lixões:

[...]A produção de gás metano $\left(\mathrm{CH}_{4}\right)$ oriundo da decomposição dos resíduos levados para lixões, por sua vez, é próximo ao impacto da atividade do vulcão Etna, na Itália, para o aquecimento global. O SELURB aponta que, se essa quantidade fosse revertida em biogás para produção de energia elétrica em aterros sanitários apropriados, seria possível abastecer a área residencial de uma cidade com 600 mil habitantes." Camila Maciel Repórter da Agência Brasil - São Paulo (2019)

Com tantas fontes, ainda precisamos danificar o planeta, o que há por trás dessa questão?

Saindo da busca por energia, podemos falar sobre a escassez de água potável, a qual também tem seus relatos de degradações, por vezes ligados à inferência humana, em busca de melhores condições de vida, mas nem sempre essenciais à sua manutenção. Podemos acrescentar desde já, que a maior fonte de energia utilizada no Brasil, ainda é produzida por usinas hidrelétricas, às quais, como seu próprio nome já enuncia, tem sua base nas águas.

Escassez de água! O que temos com isso?

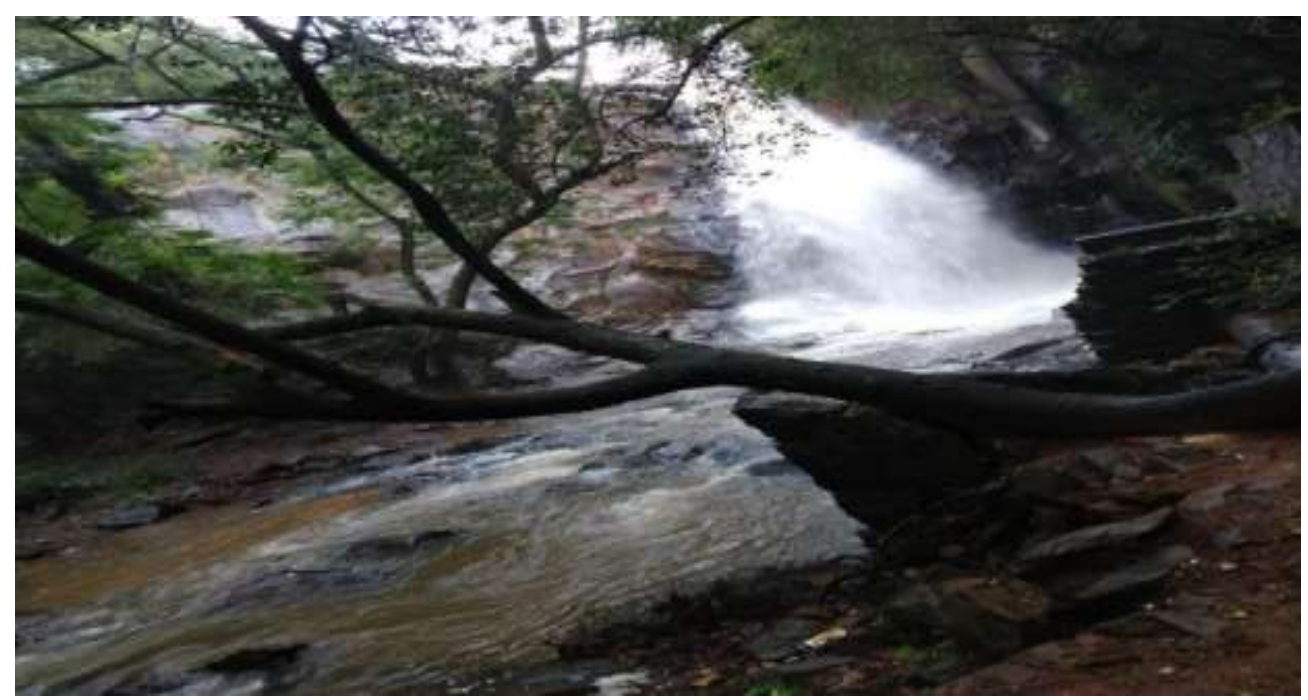

Foto cachoeira - arquivo próprio 
Vivemos numa época onde vale o status. A palavra dos poderosos vale mais que fatos.

A degradação do Meio Ambiente anda paralelo à degradação da moral, da falta de respeito pelo próximo e pelo aparecimento de salvadores da pátria.

É triste ver que assuntos como sumiço da água, aquecimento global e outros, ainda estão atrelados à discussão político/ partidária, o que torna as questões dubitáveis.

Quando falamos de meio ambiente e suas facetas, todos são defensores, exceto o povo, esse é o culpado pelos desastres que estão ocorrendo, seja por parir muito, por não ser comprometido com o assunto (desinteressado) e também por existir, como se fosse possível haver povo e alguma outra coisa humana fora dele.

A questão da água não é diferente dos demais assuntos que movem e acirraram os discursos nos palcos da vida. Tratando com descaso, cada governante diz não ser culpado pela atual situação hídrica, mas sabemos que a problemática que é realmente levada a sério no Brasil e inclusive em São Paulo, são as que têm a ver com taxas, multas e eleições, os demais serviços são levados a trancos e barrancos, pelas categorias de servidores da ponta, os quais fazem o permitido, impedidos de fazer o necessário.

É escancaradamente notado o desperdício de água na zona urbana, tanto por ligações clandestinas feitas por mangueiras, como por serviços de adutoras mal executados e a morosidade que permeia o serviço.

Conforme estudo, o GI(SPI) publica que a cidade de São Paulo desperdiça mais de um terço de água potável.

\footnotetext{
Um estudo do Instituto Trata Brasil aponta que a cidade de São Paulo desperdiçou $36,7 \%$ da água potável nos sistemas de distribuição em 2016. O prejuízo causado por essas perdas na capital, naquele ano, foi de cerca de $R \$ 450$ milhões.

[...] a pior situação na região metropolitana é da cidade de Itaquaquecetuba, onde $49,3 \%$ da água potável é desperdiçada. A melhor situação foi registrada em Guarulhos, onde $18 \%$ da água é perdida.

[...] As principais causas do desperdício são vazamentos nas tubulações, erros de leitura de hidrômetros, roubos e fraudes." https://gi.globo.com/sp/saopaulo/noticia/
}

Embora esses elementos devam representar uma grande parcela nessa demanda, não podemos deixar de citar o descaso com as águas fluviais, as quais, são comprometidas com efluentes sem tratamentos, que são despejados diretamente em seus leitos. Todavia, 
há também uma falta de cuidado com nascentes, sendo elas afligidas por moradias e prédios, até mesmo públicos, por toda parte.

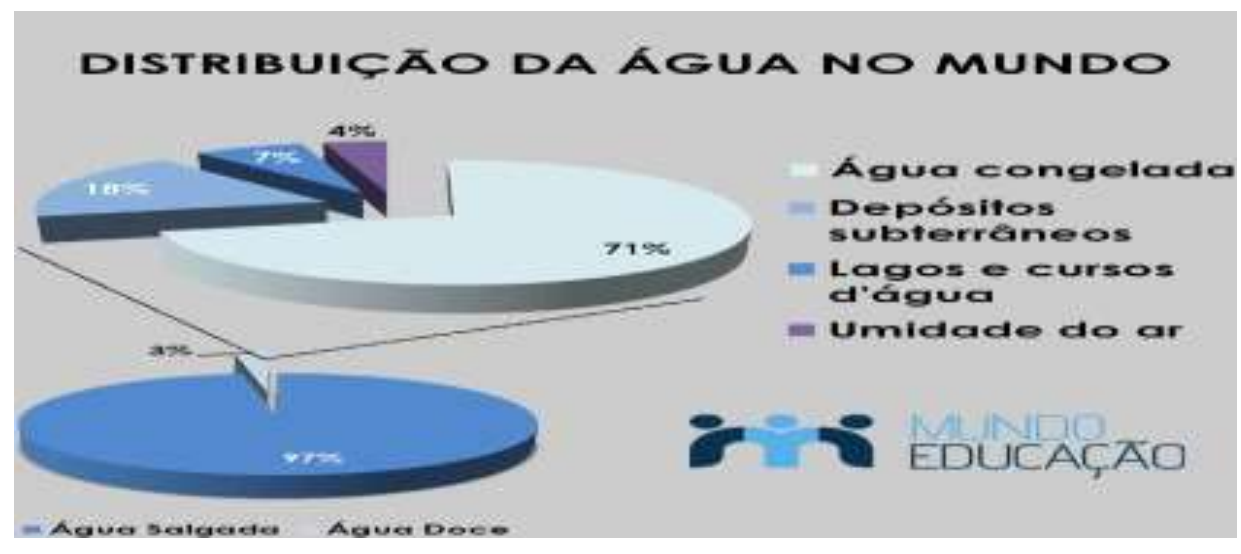

Vejamos o gráfico explicativo acessado no site mundo educação:

https://static.mundoeducacao.uol.com.br/mundoeducacao/conteudo/distribuica o-da-agua.jpg

É bom salientar que conforme literaturas, de toda a água existente no Planeta, apenas $2,5 \%$ (aproximadamente) do total de água do planeta é formado por água doce, entretanto, $70 \%$ dessa está em calotas polares, $29 \%$ no subterrâneo e só $09 \%$ em rios e lagos.

Passam governos ditos de direita ou esquerda e nada muda, todos buscam a sua perpetuação no governo e não investem em demandas, principalmente naquelas que só são notadas em estado crítico, parece ser fundamento no aprendizado dos políticos brasileiros.

Buscar culpados já não é o caso. Hoje, espera-se dos senhores e senhoras do poder, que revejam atitudes e se lembrem que foram eleitos para cuidar das causas que as pessoas comuns não possuem condições para resolver.

Não são eleitos reis ou rainhas, mas representantes que deveriam levar em suas mentes as aspirações de seus representados, cuidando de coisas como a previsão de catástrofes, tipo a que envolve a água, porém, embora importante, as necessidades não se resumem apenas nesse ponto, pois, descasos são observados sem muitos esforços, e mortes, provenientes dessas atitudes, são também notadas proporcionalmente.

Quando nos aprofundamos nesse assunto encontramos exageros cometidos com quem corta uma árvore, entretanto, há desmatamento noticiado com milhares de $\mathrm{km}$ e não ouvimos falar em punição, sugere a existência de uma espécie de proteção para tais atos. 
Sabemos que sem água não temos árvores e vice-versa, mas, por que cortar um galho dela é mais importante que contaminar uma nascente com esgotos, ou até aterrá-la? Por que a queima de produtos como pneus parece não ter o mesmo peso, sendo que esse polui o ar, o solo, e o óleo produzido dessa queima pode chegar até o lençol freático?

Sempre que buscamos falar de certo ou errado, precisamos lembrar que tudo depende do ângulo que estamos analisando as coisas. É tudo muito relativo...

Todos sabemos como cuidar do planeta e torná-lo sustentável, e diria mais, hoje não há mais inocentes, às informações estão abertas a todos, mas nem sempre essas produzem conhecimento, entretanto, talvez seja assim para a manutenção da dualidade, coisa própria da existência humana, temos sempre os prós, os contra e aqueles que tem sempre opinião fechada sobre as coisas.

A informação parece não produzir conhecimentos, mas alienados. Paralelo ao já apresentado, nota-se que há interesses que pegam carona na dicotomia, certo/errado, bem (Bom) e mal (mau) e imprime seu ritmo, salientando essa ou aquela situação, distanciando a questão real da ideal.

Estamos sempre seguindo regras criadas por países que já extrapolaram no direito de poluir, e nós, quando tivemos esse direito? A ninguém é dado o direito de degradar, mas em tudo que fazemos incute algum tipo de degradação, porquanto, se observarmos mais de perto é o pensamento da produção que a acelera, sem comparação com as culturas de subsistências.

O pescador sempre soube o que fazer para não faltar o peixe no seu rio, o agricultor familiar nunca queimou mais que o necessário para seu plantio, e podemos perceber que a queima está paulatinamente sendo abolida, mas, seria uma ignorância sem tamanho, achar que as mudanças se deram por acaso, entretanto, não se pode atribuir tal evento à educação ambiental apresentada na escola, pois essa ainda não atinge sequer Ioo\% da atual geração, e tal ação já existia mesmo antes da dita 'civilização', ou seja, invasão europeia. Aqui não estamos discutindo a relevância já comprovada da Educação Ambiental, mas a imposição, em detrimento da história.

Os europeus invadiram, mudaram costumes, implantaram a cultura da produção em grande escala, aculturaram, impuseram um ritmo, degradaram o quanto puderam e hoje, para responder ao ululante discurso de preservação, os governos brasileiros punem a 
quem corta uma árvore, enquanto mascaram a história dos quilômetros de queimadas, da derruba ilegal de madeira, da falta de cuidado com as nascentes existentes no setor urbano. Exageros de um lado e descaso em outro, esquecem-se da inter-relação, mas preservam o nome de país ambientalista. Verdade? Como assim?

É a prática da proteção a interesses, se assim não fosse, teríamos um discurso holístico e atento a interação socio/cultural/ambiental e prestaríamos atenção que uma nascente não existe sem as árvores, mas essas não existiriam sem as nascentes, e formando mais uma tríade, vamos incluir as abelhas, as responsáveis pela polinização, sem elas as arvores se acabam.

Então, enquanto nos dispomos a proteger arvores, não podemos nos esquecer que essas, não são autossuficientes, faz-se necessário a ampliação da visão e a inclusão nessa discussão sobre como socorrermos os heminópteros, em especial as abelhas, responsáveis junto a outras espécies pela polinização e, como que por tabela estaremos também indiretamente salvando as árvores e também as nascentes.

Apis mellífera em vôo de aproximação a uma flor de maracujá - Foto: Charles Martins de Oliveira

As abelhas são tratadas como pragas, todos sabem que elas se mudam, e nesse momento são chamadas de enxame viajante. Esse grupo pode a qualquer momento estacionar temporariamente em um ponto, em um dia e no outro já haver seguido viagem, mas na maioria das vezes, no setor urbano, são atacadas pelos Agentes de zoonoses, com seus venenos, e dali as tiram em sacos, já mortas, isso por que os mesmos que protegem uma arvore, denunciaram e exigiram que o poder público tomasse uma atitude, e esse, em uma ação semelhante a um carro desgovernado, as mata, para alivio do maior inimigo do planeta, os humanos.

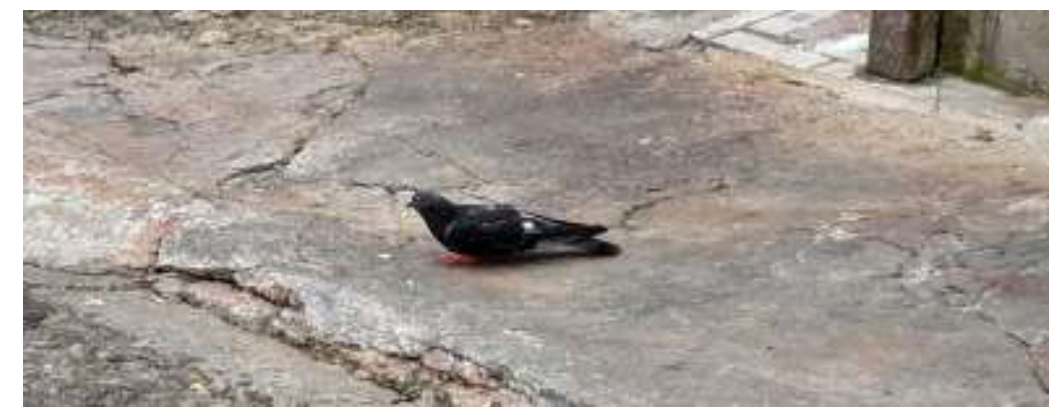

Foto arquivo próprio - Pombo Columbia Livia 
O Pombo europeu, Columba Livia é uma praga, introduzido no Brasil pelos europeus no século XVI, pela família real portuguesa.

Algumas literaturas afirmam que os trouxeram para servir de petiscos, mas há menção em outras indicando que a intenção era enfeitar as cidades com essas aves, era criação doméstica, fato é que, hoje, é responsável por uma série de doenças pulmonares causadas por bactérias existentes em suas fezes. Esse pássaro está também envolvido no processo de extinção de outras espécies, e que já haviam se adaptado ao convívio humano nas cidades, como o pardal.

O Pardal também é uma espécie estrangeira que bem se adaptou no território brasileiro, mas em sua alimentação podemos notar que estão incluídos mosquitos, e por seu tamanho pode ser controlado por animais caçadores como os gatos domésticos. Será que essa pequena ave já ajudou algum tempo no controle do Culex (pernilongo)?

Deixando em paz aqueles que já estão em processo de extinção, voltemos aos pombos, do qual, não há registro de benefício para os seres humanos trazidos por este elemento, mas são incluídos na proteção da lei e não se pode matá-los, sequer há uma indicação de como controlar sua reprodução, além de que, é facilmente encontrável pessoas alimentando essa espécie em praça pública, mesmo assim, reclamam de seus dejetos e seus ninhos barulhentos, enquanto as abelhas são atacadas por pesticidas em seu habitat natural, e no setor urbano, são exterminadas. Fala sério, que proteção ambiental é essa...

Não podemos afirmar ou defender uma tese de que não há iniciativa popular danosa ao meio ambiente, mas será que concordamos que os mesmos que indicam mecanismos para despoluir e para conservar, além de terem maior parcela de culpa, estão usando o assunto mais uma vez em benefício próprio?

Há uma hipótese que pode ser verdade: Sempre que o homem quer intervir e modelar a natureza, viabiliza histórias como a dessa espécie de pombos. Cria predadores tanto para outros viventes, como para si mesmo.

Você leitor, lembra ou já ouviu falar de quando embrulhavam alimentos nos açougues, nas padarias e mercearias com papel pardo, e o leite era vendido em garrafas, ou em tonéis pendurados, às vezes em animais? Hoje isso já não existe, temos leite vendido 
em cada esquina, em embalagens de plástico e em tetra pak. Lembrando que o consumidor não pediu às sacolas plásticas, tudo surgiu conforme as mudanças nos meios de produção.

Vemos e sentimos o que está acontecendo com o planeta, mas quando o assunto está em pauta, eis que aparecem exagerados ou céticos, sempre na busca por culpados, nunca colaborando com a introspecção.

Notoriamente as pequenas ações realizadas em casa, farão a diferença, tais como: Separar o lixo, explorar o potencial de espaços para produção de algo para o consumo, diminuir o consumo de produtos que não tragam embalagem biodegradável e, ou que tenham um histórico de sofrimento, seja humano, ambiental ou animal, dar um destino correto, sempre que possível aos resíduos domésticos, assimilar costumes saudáveis como ir ao trabalho de transporte público, ou deixar de usar seu automóvel em suas folgas, e até trocar produtos descartáveis por duráveis e outras.
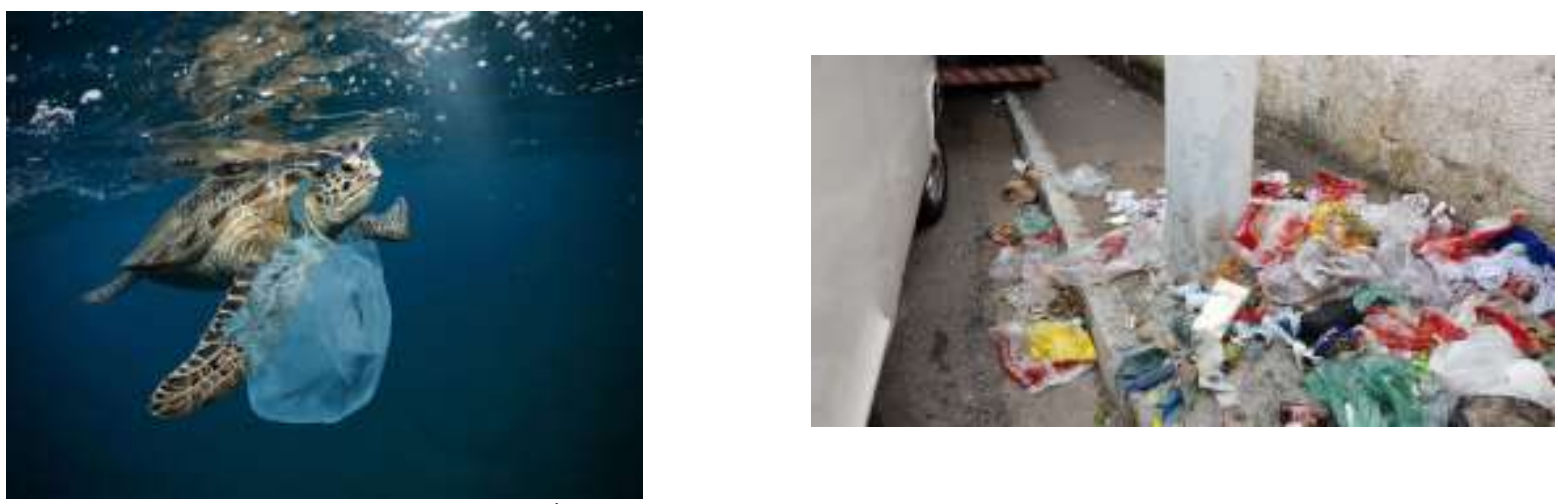

Foto - Arquivo Pensamento Verde - https://www.google.com/search?q=animais+e+sacolas+plasticas\&r

Em resumo podemos nos preocupar em diminuir o lixo produzido, com isso diminuiremos também nossa pegada ecológica. Sempre há como colaborar...

O discurso é hegemônico, mas os meios são dificultados e a produção de subsistência perde espaço para a produção de mercado! O status vence a Sustentabilidade, mas o descaso popular e a ignorância também dão as cartas.

O povo comum não possui ferramentas para ajudar o planeta, são muitas as dificuldades para essa categoria intervir na situação, entretanto, basta que desvie um pouco o olhar do seu próprio umbigo e teremos uma mudança radical, ou na pior das hipóteses, notaremos alterações oriundas dessa ação, seja no dia-a-dia em relação ao 
ambiente natural, seja nas ações dos políticos, já que esses, apenas pegam carona nos costumes mantidos em nossas casas e na falta de interesse apresentado pela maioria.

A falta de opinião pessoal sobre o assunto é fator relevante e doutrinador nessa discussão. Pense um pouco no que e como você está colaborando com a demanda, mas, não esqueça que, só veremos o todo quando ouvirmos os outros.

Parafraseando William Shakespeare podemos dizer que há mais coisas envolvendo a história da proteção ambiental do que apresenta nossa vã filosofia.

\section{REFERENCIAS}

SAMAHA E. D. - Paulistanos, cuidado: corte de árvore sem autorização pode ensejar sérios problemas! http://www.dazibao.com.br/site/paulistanos-cuidado-corte-de-arvoresem-autorizacao-pode-ensejar-serios- \%24\%2010.00o\%acesso 06/02/2022

PONTES, Nádia - As acusações que pesam sobre Ricardo Sales - publicado o8/o7/2020 https://www.dw.com/pt-br/as-acusa\% $\mathrm{C}_{3} \% \mathrm{~A}_{7} \% \mathrm{C}_{3} \% \mathrm{~B}_{5}$ es-que-pesam-sobre-ricardo-er/a54087202 acesso $07 / 02 / 2022$

CAIN, Michelle https://revistagalileu.globo.com/Ciencia/MeioAmbiente/noticia/202I/II/por-que-reduzir-emissoes-de-metano-nao-basta-contra-oaquecimento-global.html acesso $06 / 02 / 2022$

\section{https://naofrackingbrasil.com.br/o-que-e-fracking/ acesso 06/02/2022}

MACIEL, Camila - https://agenciabrasil.ebc.com.br/geral/noticia/2019-o6/lixoesliberam-6-milhoes-de-toneladas-de-gas-de-efeito-estufa-ao-ano acesso 06/02/2022

A distribuição da água no mundo - https://mundoeducacao.uol.com.br/geografia/adistribuicao-agua-no-mundo.htm acesso em 06/02/2022

SILVA, Jailton J. et al - Descarte Irregular de Pneus no Distrito Cidade Tiradentes - São Paulo - SP - 2016 https://www.webartigos.com/artigos/descarte-irregular-depneus/159809 acesso 09/02/2022

PARRA, Cristina V.- NASCIMENTO, Ana Paula B. do - FERREIRA Mauricio L. REUTILIZAÇÃO E RECICLAGEM DE PNEUS, E OS PROBLEMAS CAUSADOS POR SUA DESTINAÇÃO INCORRETA https://portalidea.com.br/cursos/reciclagemde-pneus-apostila03.pdf acesso em 09/02/22

PENSAMENTO VERDE https://www.google.com\%2Freciclagem\%2Fquem-e-maisvilao-nos-ou-assacolasplasticas\%2F \&psig=AOvVawih2VtNASW9i2J2Ycw Yqoof\&ust $=1644677326318000$ 
\&source $=$ images $\& \mathrm{~cd}=\mathrm{vfe} \& \mathrm{ved}=\mathrm{oCAsQjRxqFwoTCJD3vYLz9 \_ UCFQAAAAAdAAAA}$ ABAT Acesso II/02/2022

EMBRAPAhttps://www.embrapa.br/cerrados/colecaotomologica/hymenoptera\#: :text= Os\%2ohimen\%C3\%B3pteros\%20(do\%2ogrego\%2ohymen,cada\%2ogrupo\%2C\%2.09\%C3\%A Anero\%200u\%20esp\%C3\%A9cie. Acesso II/02/2022

https://www.google.com/url?sa=i\&url=https\%3A\%2F\%2Fpt.m.wikipedia.org\%2Fwiki\%2 FFicheiro\%3 AColumbaliviapomba.JPG\&psig=AOvVawoh2 OMBgFATbAK 3 WeWMztf O\&ust $=1644702701174000 \&$ source $=$ images\& $c d=v f e \& v e d=o C A s Q j R x q F w o T C K C 8 q J T R-$ PUCFQAAAAAdAAAAABAI acesso II/02/2022

https://www.opovo.com.br/noticias/brasil/2021/o4/o2/voce-sabia--pombos-nao-saonativos-do-brasil--foram-trazidos-para-ca--conheca-a-historia.html

https://mundoeducacao.uol.com.br/biologia/pombo-domestico.htm

LIMA, Bruno Carlos S. de - Conheça o pequeno pássaro Pardal https://blog.cobasi.com.br/pardal/\#: :text=O\%20pardal\%20tamb\%C3\%A9m\%20pode\%20 se,\%2C\%2obanana\%2C\%20ma\% $\mathrm{C}_{3 \%}$ A $\mathrm{A}_{7} \% \mathrm{C}_{3} \% \mathrm{~A}_{3} \% 20 e \% 20$ acerola. Acesso 13/02/2022 